\title{
Nutrição e produtividade de plantas de pimentão colorido, adubadas com biofertilizante de suíno
}

\author{
Maria A. N. Sediyama ${ }^{1}$, Marlei R. dos Santos², Sanzio M. Vidigal ${ }^{3}$, Cláudia L. de O. Pinto ${ }^{4} \&$ Luciano L. Jacob $^{5}$ \\ ${ }^{1}$ EPAMIG, Unidade Regional Zona da Mata. Viçosa, MG. E-mail: mariasediyama@gmail.com (Autor correspondente) \\ ${ }^{2}$ UESPI. Uruçuí, PI. E-mail: marleirs@yahoo.com.br \\ ${ }^{3}$ EPAMIG, Unidade Regional Zona da Mata. Viçosa, MG. E-mail: sanziomv@gmail.com \\ ${ }^{4}$ EPAMIG, Unidade Regional Zona da Mata. Viçosa, MG. E-mail: clucia@gmail.com \\ ${ }^{5}$ EPAMIG, Unidade Regional Zona da Mata. Viçosa, MG. E-mail: lucianoepamig@yahoo.com.br
}

\section{Palavras-chave:}

Capsicum annuum $\mathrm{L}$. adubação orgânica dejeto de suíno fermentação

\begin{abstract}
R E S U M O
O biofertilizante de suíno pode ser utilizado em cultivos agrícolas respeitando critérios de qualidade e quantidade necessárias ao solo e à planta. Com este trabalho objetivou-se avaliar a nutrição e a produtividade de frutos em duas cultivares de pimentão colorido, adubadas com biofertilizante de suíno utilizando-se de técnicas de cultivo orgânico. Duas cultivares híbridas foram avaliadas: Amanda (frutos amarelos) e Rubia (frutos vermelhos) e quatro doses de biofertilizante $\left(0,30,60\right.$ e $\left.120 \mathrm{~m}^{3} \mathrm{ha}^{-1}\right)$ aplicadas no solo antes do plantio e em cobertura, após o transplante das mudas. Observou-se resposta para doses de biofertilizante com efeitos positivos na nutrição das plantas e na produtividade de frutos. A cultivar Rubia apresentou maior índice SPAD e maior teor de $\mathrm{N}$ nas folhas em relação à cv. Amanda $(\mathrm{P}<0,05)$. A produtividade de frutos extras foi de $15,39 \mathrm{tha}^{-1} \mathrm{com}$ a dose de $110 \mathrm{~m}^{3} \mathrm{ha}^{-1}$ de biofertilizante para as duas cultivares. Quanto à produtividade comercial a cv. Rubia foi mais produtiva (21,45 tha $\left.{ }^{-1}\right)$ que a Amanda $(17,22$ $\left.\mathrm{t} \mathrm{ha}^{-1}\right)$. A aplicação do biofertilizante de suíno proporciona plantas com estado nutricional e potencial produtivo adequado podendo, desta forma, ser recomendado na fertilização não convencional do pimentão colorido.
\end{abstract}

\section{Key words:}

Capsicum annuum $\mathrm{L}$. organic fertilizer

swine waste

fermentation

\section{Nutrition and yield of colored pepper fertilized with swine bio-fertilizer}

\begin{abstract}
A B S T R A C T
Swine bio-fertilizer can be used as organic fertilizer, based on the criteria of quality and quantity necessary for the soil and plant. The objective of this study was to evaluate nutrition and yield of two colored pepper cultivars, fertilized with swine bio-fertilizer, using organic cultivation techniques. Two hybrid cultivars were evaluated: Amanda (yellow fruit) and Rubia (red fruit) and four bio-fertilizer doses $\left(0,30,60\right.$ and $\left.120 \mathrm{~m}^{3} \mathrm{ha}^{-1}\right)$ applied in the soil before planting and under cover after seedling transplant. There was response for bio-fertilizer doses with positive effects on the nutrition of pepper plant and fruit yield. Cultivar Rubia presented a higher SPAD index and higher N content in the leaves than cv. Amanda ( $\mathrm{p}<0.05)$. Yield of extra fruits was $15.39 \mathrm{t} \mathrm{ha}^{-1}$, with bio-fertilizer dose of $110 \mathrm{~m}^{3} \mathrm{ha}^{-1}$ for the two cultivars. As for commercial yield, cv. Rubia was more productive (21.45 $\left.\mathrm{t} \mathrm{ha}^{-1}\right)$ than Amanda (17.22 $\mathrm{t}$ $\left.\mathrm{ha}^{-1}\right)$. It was concluded that the application of swine bio-fertilizer provides to plants an adequate nutritional state and yield potential; thus, it can be recommended for non conventional fertilization for the cultivation of yellow and red pepper plants under field conditions.
\end{abstract}

\section{INTRODUÇÃO}

A cultura do pimentão se mantém dentre as dez culturas de hortaliças de maior importância econômica no mercado brasileiro. Os frutos são comercializados verdes (70\%) e maduros (30\%). Os frutos maduros, por permanecerem mais tempo na planta até seu amadurecimento total, estão associados ao estresse das plantas e consequente redução da produtividade (Henz et al., 2007). Entretanto, é considerável a demanda por pimentões coloridos que apresentam maior valor no mercado.

São inúmeros os híbridos de pimentão de frutos coloridos e de boa aceitação comercial, porém informações técnicas relativas ao seu desempenho em sistema orgânico, ainda são escassas. Normalmente se empregam, no cultivo do pimentão, tecnologias apuradas as quais devem estar voltadas para questões de sustentabilidade com fins de reduzir os custos e ampliar a produtividade. Assim, o emprego da adubação orgânica pode contribuir para alcançar tal objetivo de vez que a adubação convencional é onerosa. De acordo com Ribeiro et al. (2000) a aplicação de adubos e corretivos na cultura do pimentão representa, em média, $23,4 \%$ do custo total de produção.

$\mathrm{O}$ uso de fertilizantes orgânicos de origem animal é uma prática útil e econômica para os pequenos e médios produtores de hortaliças, por propiciar a melhoria da fertilidade e a conservação do solo (Araújo et al., 2007). Entretanto, esta 
prática, quando utilizada durante vários anos consecutivos, ocasiona o acúmulo de nitrogênio orgânico no solo pelo aumento do potencial de mineralização e da disponibilidade deste nutriente para as plantas. A determinação da taxa de mineralização de nitrogênio em solos tratados com resíduos é fundamental para definir as doses a serem aplicadas fornecendo $\mathrm{N}$ às plantas na época adequada sem perdas do elemento por lixiviação (Moretti et al., 2013).

Em algumas pesquisas é demonstrada a eficiência de fertilizantes orgânicos e ou minerais, para atendimento à demanda de nutrientes em hortaliças (Ribeiro et al., 2000; Oliveira et al., 2004; Sediyama et al., 2009a, b; Vidigal et al., 2010). Oliveira et al. (2004) obtiveram produtividades máximas de 25,5 e de $10,7 \mathrm{t} \mathrm{ha}^{-1}$ de pimentão, cultivar All Big, com a aplicação de 5\% de urina de vaca, na presença e ausência de NPK, respectivamente, sendo a produtividade média de 19,8 t ha $^{-1}$ de frutos comerciais, na presença de NPK e de urina de vaca.

Por outro lado, Sediyama et al. (2009b) obtiveram produtividade máxima de frutos comerciais de pimentão verde $\left(60,41 \mathrm{t} \mathrm{ha}^{-1}\right)$ quando associaram $84,43 \mathrm{t} \mathrm{ha}^{-1}$ de composto orgânico com $1500 \mathrm{~kg} \mathrm{ha}^{-1}$ da fórmula 4-14-8 (N-P-K) aplicados nos sulcos de plantio. Factor et al. (2008) avaliaram a produtividade e a qualidade de frutos de pimentão vermelho, híbrido 'Margarita', em substratos adubados com três soluções nutritivas e verificaram que a substituição parcial de fertilizantes minerais pelo efluente de biodigestor à base de dejetos de suíno, não foi suficiente para proporcionar produtividade equivalente à adubação 100\% mineral; apesar de que alcançou padrões de qualidade semelhantes e com boa produtividade. $\mathrm{O}$ uso do efluente de biodigestor à base de dejetos de suíno pode ser considerado uma alternativa em potencial para reduzir os custos de produção no cultivo em substratos e, principalmente, evitar o descarte deste material ainda rico em nutrientes no meio ambiente.

A adubação de hortaliças é feita, em alguns casos, com doses de fertilizantes acima daquelas recomendadas pela análise do solo para melhorar a produtividade e prevenir deficiências nutricionais, mas o uso de doses excessivas pode ser prejudicial às plantas e ao ambiente, além de desperdícios.

A utilização de resíduos na atividade agrícola é interessante do ponto de vista econômico por proporcionar aumento de produtividade das plantas e reduzir o custo com fertilizantes, além da deposição segura desses materiais no ambiente (Figueiredo \& Tanamati, 2010). Na microrregião de Ponte Nova, Zona da Mata mineira, existe grande disponibilidade de dejetos resultantes da criação de suínos em sistemas de confinamento. Este fato deixa para o produtor, como principal alternativa, sua aplicação no solo, como fertilizante orgânico. No entanto, os dejetos precisam ser fermentados previamente para evitar contaminação do solo, das plantas e da água. Quando devidamente fermentados podem ser usados na produção de biofertilizantes e de compostos orgânicos para adubação via solo e produção de culturas, associado ao seu alto valor fertilizante (Sediyama et al., 2009a).

A fermentação aeróbica ou anaeróbica dos dejetos de suínos possibilita seu uso no solo como fonte de nutrientes para a produção de determinadas hortaliças, como pimentão e quiabo (Sediyama et al., 2009a, b). Esta prática é útil, de baixo custo e proporciona redução do custo de produção além de melhorar a qualidade de vida, em especial por reduzir a poluição ambiental, causada pelo lançamento dos dejetos nos cursos d'água.

Há poucas informações a respeito da aplicação de doses de biofertilizante via solo na cultura do pimentão. A condução de estudos para definir as doses específicas para culturas são úteis na avaliação do seu estado nutricional considerando-se que, quanto maior a capacidade da planta em acumular um nutriente, maiores serão as diferenças na concentração desse nutriente em resposta às taxas variáveis de adubação (Marcussi, 2005).

Com base no exposto objetivou-se avaliar a nutrição e a produtividade de frutos em duas cultivares de pimentão colorido; Amanda (amarelo) e Rubia (vermelho) adubadas com biofertilizante de suíno via solo, com o emprego de técnicas de cultivo orgânico.

\section{Material e Métodos}

O experimento foi conduzido a campo, no período de abril a novembro de 2010. A unidade de pesquisa está situada a $20^{\circ} 30^{\prime}$ de latitude $S$ e $43^{\circ} 00^{\prime}$ de longitude $\mathrm{O}$; a altitude é de $500 \mathrm{~m}$ em relação ao nível do mar, com temperatura média máxima anual de $21,8^{\circ} \mathrm{C}$ e mínima anual de $19,5^{\circ} \mathrm{C}$; a precipitação média anual é de $1.250 \mathrm{~mm}$ (Cunha et al., 2000). O solo da área experimental, Argissolo Vermelho-Amarelo Câmbico, fase terraço apresentou, na camada de 0 a $20 \mathrm{~cm}$, as seguintes características: $\mathrm{pH}$ (água $1: 2,5)=6 ; \mathrm{P}=17,2 \mathrm{mg} \mathrm{dm}^{-3} ; \mathrm{K}=178 \mathrm{mg} \mathrm{dm}^{-3} ; \mathrm{Ca}^{2+}=2,9 \mathrm{cmol}_{c}$ $\mathrm{dm}^{-3} ; \mathrm{Mg}^{2+}=0,9 \mathrm{cmol}_{\mathrm{c}} \mathrm{dm}^{-3} ; \mathrm{Al}^{3+}=0 \mathrm{cmol}_{\mathrm{c}} \mathrm{dm}^{-3} ; \mathrm{CTC}(\mathrm{t})=4,26$ $\mathrm{cmol} \mathrm{dm}_{c}^{-3} ; \mathrm{CTC}(\mathrm{T})=6,9 \mathrm{cmol} \mathrm{dm}_{c}^{-3} ; \mathrm{V}=62 \% ; \mathrm{P}-\mathrm{rem}=35 \mathrm{mg}$ $\mathrm{L}^{-1} \mathrm{e} \mathrm{MO}=16 \mathrm{~g} \mathrm{~kg}^{-1}$.

O biofertilizante foi obtido do dejeto líquido de suíno proveniente da lavagem das baias; após a coleta procedeu-se à fermentação anaeróbica, durante 30 dias, em caixas de fibra de vidro fechadas com a tampa para impedir a entrada de ar; após a fermentação o biofertilizante apresentou as seguintes características: $\mathrm{N}=1.774,08 \mathrm{mg} \mathrm{L}^{-1} ; \mathrm{P}=164,65 \mathrm{mg} \mathrm{L}^{-1} ; \mathrm{K}=$ $1.092,00 \mathrm{mg} \mathrm{L}^{-1} ; \mathrm{Ca}=106,67 \mathrm{mg} \mathrm{L}^{-1} ; \mathrm{Mg}=35,8 \mathrm{mg} \mathrm{L}^{-1} ; \mathrm{Na}=$ $432,00 \mathrm{mg} \mathrm{L}^{-1} ; \mathrm{Zn}=10,24 \mathrm{mg} \mathrm{L}^{-1} ; \mathrm{Fe}=4,59 \mathrm{mg} \mathrm{L}^{-1} ; \mathrm{Mn}=1,62$ $\mathrm{mg} \mathrm{L}^{-1} \mathrm{e} \mathrm{Cu}=1,41 \mathrm{mg} \mathrm{L}^{-1} ; \mathrm{pH}$ (água) $=6,72$; densidade $=1,1 \mathrm{~g}$ $\mathrm{cm}^{-3}$ e condutividade elétrica $=15,4 \mathrm{dS} \mathrm{m}^{-1}$. As quantidades totais de nutrientes em cada dose de biofertilizante estão indicadas na Tabela 1.

Utilizou-se o delineamento experimental de blocos casualizados com quatro repetições, no esquema fatorial $2 \mathrm{x}$ 4, sendo duas cultivares híbridas: Amanda (frutos amarelos) e Rubia (frutos vermelhos) e quatro doses de biofertilizante de suíno $\left(0 ; 30 ; 60\right.$ e $\left.120 \mathrm{~m}^{3} \mathrm{ha}^{-1}\right)$. Cada parcela de $16 \mathrm{~m}^{2}$ se constituiu de quatro linhas de $4,0 \mathrm{~m}$ de comprimento nas quais foram cultivadas 32 plantas no espaçamento de $1,0 \times 0,5 \mathrm{~m}$. Foram consideradas úteis as 12 plantas centrais de cada parcela.

Foram aplicados $300 \mathrm{~kg} \mathrm{ha}^{-1}$ de $\mathrm{P}_{2} \mathrm{O}_{5}$, na forma de termofosfato natural (Yorim Master ${ }^{\circledR}$ ) nos sulcos para todos os tratamentos uma semana antes do plantio, com base no teor de fósforo presente no solo e no biofertilizante de suíno (Tabela 
Tabela 1. Quantidades de nutrientes fornecidas em cada dose de biofertilizante de suíno aplicada na cultura do pimentão

\begin{tabular}{crcr}
\hline \multirow{2}{*}{ Nutrientes } & \multicolumn{3}{c}{ Doses $\left(\mathbf{m}^{\mathbf{3}} \mathbf{h a}^{-1}\right)$} \\
\cline { 2 - 4 } & \multicolumn{3}{c}{$\mathbf{6 0}$} \\
$\mathrm{N}$ & 53,22 & 106,44 & $\mathbf{1 2 0}$ \\
$\mathrm{P}$ & 4,95 & 9,90 & 212,88 \\
$\mathrm{~K}$ & 32,76 & 65,52 & 19,80 \\
$\mathrm{Ca}$ & 3,21 & 6,42 & 131,04 \\
$\mathrm{Mg}$ & 1,08 & 2,16 & 12,84 \\
$\mathrm{Zn}$ & & $\mathrm{g} \mathrm{ha} \mathrm{h}^{-1}$ & 4,32 \\
\hline $\mathrm{Fe}$ & 307,2 & 614,4 & 1228,8 \\
$\mathrm{Mn}$ & 137,7 & 275,4 & 550,8 \\
$\mathrm{Cu}$ & 48,6 & 97,2 & 194,4 \\
& 42,3 & 84,6 & 169,2 \\
\hline
\end{tabular}

1), segundo recomendação de Ribeiro et al. (1999). A adubação orgânica foi feita com $1 / 4$ da dose do biofertilizante incorporado ao sulco 15 dias antes do transplantio das mudas (DAT). Posteriormente, foram realizadas três adubações de cobertura com volume igual ao do biofertilizante, a cada 20 dias, ou seja, as adubações de cobertura ocorreram via solo aos 20,40 e 60 DAT. Assim, o intervalo de tempo entre a última aplicação e a primeira colheita dos frutos maduros foi de 50 dias.

As mudas foram produzidas em bandejas de polipropileno expandido com 128 células, preenchidas com substrato orgânico proveniente de húmus de minhoca e levadas para o campo 38 dias após a semeadura. A irrigação foi feita por microaspersão com turno de rega de dois dias. O manejo das plantas invasoras, quando necessário, foi feito com auxílio de enxada. Aos 40 dias após o transplante (DAT) avaliou-se o Índice Relativo de Clorofila (IRC) ou índice SPAD, em clorofilômetro. As leituras foram realizadas em dois pontos do limbo de cinco folhas jovens totalmente expandidas no horário entre 9 e 10 h $30 \mathrm{~min}$; em seguida, as folhas usadas para determinação do IRC foram coletadas para análise de nutrientes, acondicionadas em sacos de papel e secadas em estufa com circulação de ar, na temperatura de $65-70{ }^{\circ} \mathrm{C}$, durante $72 \mathrm{~h}$; posteriormente as amostras foram moídas e analisadas quanto aos teores de N, P, K, Ca, Mg, S, Mn, B, Zn e Fe, segundo procedimentos da EMBRAPA (2009) cujos resultados foram expressos em teor de nutrientes na matéria seca das folhas (Fontes, 2001). Nesta mesma época, 40 DAT, foram avaliadas a altura das plantas e a altura da inserção do primeiro fruto.

A partir dos 40 DAT foram feitas aplicações quinzenais de Calda Viçosa de forma preventiva contra doenças fúngicas da parte aérea enquanto o controle preventivo de insetos foi feito com aplicações quinzenais de óleo de Nim (Mossini \& Kemmelmeier, 2005).

A colheita foi realizada quando mais de $70 \%$ da área dos frutos apresentavam a cor característica da cultivar, amarelo (Amanda) ou vermelho (Rubia) com início aos 151 dias após a semeadura. Avaliou-se a produção de frutos comercializáveis e não comercializáveis. Os frutos comercializáveis foram classificados com base no comprimento e no diâmetro, em: extra (frutos graúdos) - frutos com 15 a17 cm de comprimento e diâmetro igual ou superior a $7 \mathrm{~cm}$; especial (frutos médios)
- frutos com 12 a $15 \mathrm{~cm}$ de comprimento e diâmetro igual ou superior a $6 \mathrm{~cm}$ e primeira (frutos miúdos) - frutos com 8 a $12 \mathrm{~cm}$ de comprimento e diâmetro igual ou superior a 4 $\mathrm{cm}$, segundo CEAGESP (2010), com pequenas modificações. Calculou-se a produtividade precoce de frutos pela soma das produções obtidas nas três primeiras colheitas.

Por ocasião da penúltima colheita avaliaram-se, também, a altura das plantas e os teores de sólidos solúveis (SS) nos frutos maduros ( $\left.{ }^{\circ} \mathrm{Brix}\right)$. Amostras da polpa dos frutos foram cortadas com faca e colocadas em espremedor de alho, inox, para retirada do suco determinando-se o teor de sólidos solúveis totais em refratômetro manual Atago, modelo 3T ajustado à temperatura de $25^{\circ} \mathrm{C}$, e expressos em ${ }^{\circ}$ Brix.

Os dados foram submetidos às análises de variância e regressão, em que as variáveis independentes foram as doses de biofertilizante. Os modelos foram escolhidos com base na significância dos coeficientes de regressão utilizando-se o teste "t" $(\mathrm{p}<0,05)$.

\section{Resultados e Discussão}

Observou-se diferença significativa $(\mathrm{p}<0,05)$ entre as doses de biofertilizante em relação ao estado nutricional das plantas e à produtividade de frutos de pimentão, além de aumento linear para Índice Relativo de Clorofila (IRC) ou Índice SPAD com o aumento das doses de biofertilizante para a cv. Amanda, com maior valor estimado $(55,43)$ na maior dose aplicada e o menor valor $(51,45)$ na testemunha (Figura 1A). De acordo com Marcussi et al. (2004) o índice SPAD pode ser usado como indicador da concentração de nitrogênio nas folhas, o que auxilia no manejo da adubação nitrogenada (Fontes \& Araújo, 2006).

Para teor foliar de $\mathrm{N}$ não ocorreu efeito do biofertilizante na cv. Amanda com valor médio de $42,69 \mathrm{~g} \mathrm{~kg}^{-1}$ inferior aos teores de $\mathrm{N}$ observados na cv. Rubia, que apresentou teor máximo de $46,14 \mathrm{~g} \mathrm{~kg}^{-1}$, estimado com $80 \mathrm{~m}^{3} \mathrm{ha}^{-1}$ de biofertilizante (Figura 1B). Observou-se correlação de $0,8394(\mathrm{P}<0,05)$ entre o índice SPAD e o teor foliar de N para a cv. Amanda e correlação não significativa para a cv. Rubia; entretanto, as plantas da cv. Rubia apresentaram folhas com coloração verde mais intensa (valores SPAD maiores) e maiores teores foliares de N; na cv. Amanda, embora o índice SPAD tenha aumentado com a dose de biofertilizante, houve constância e menor intensidade da coloração verde nas folhas, característica esta observada no campo mesmo que, para as duas cultivares, os teores foliares de $\mathrm{N}$ se tenham apresentado acima da concentração crítica $(40,0$ $\mathrm{g} \mathrm{kg}^{-1}$ ) descrita por Fontes (2001) independente da aplicação do biofertilizante.

Waquin \& Andrade (2004) ressaltam que todos os fatores que afetam o teor de clorofila influenciam a intensidade da cor verde da planta e, por consequência, os valores da leitura SPAD. Assim, os valores apresentados como limites entre suficiência e deficiência, ou seja, as concentrações críticas são apenas referenciais e devem ser ajustadas a cada condição, sobremaneira para o cultivo no sistema orgânico. 
A.

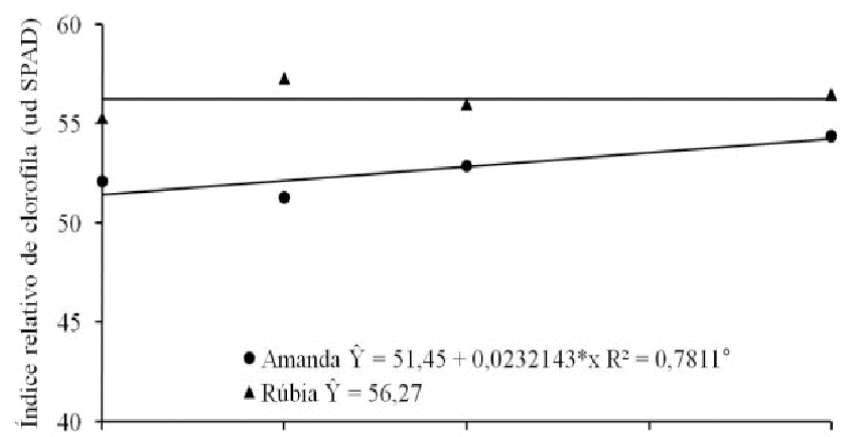

C.

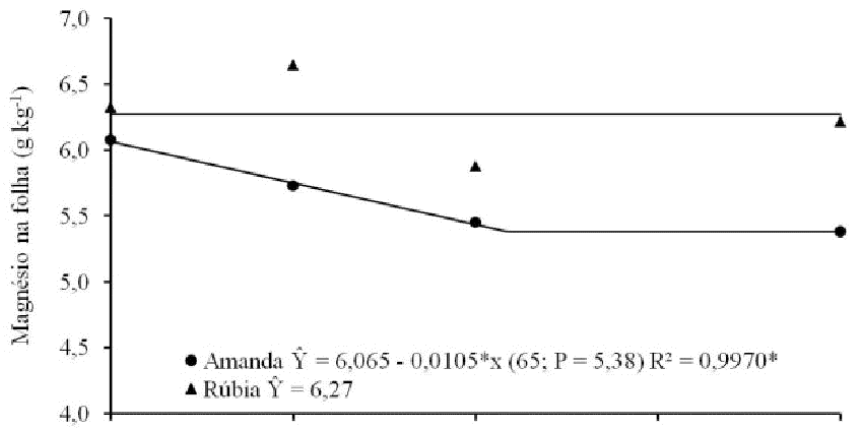

E.

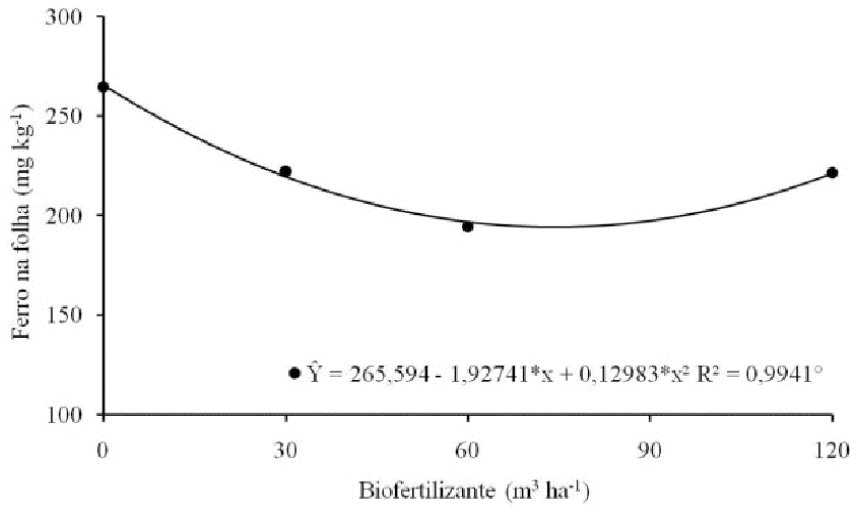

B.

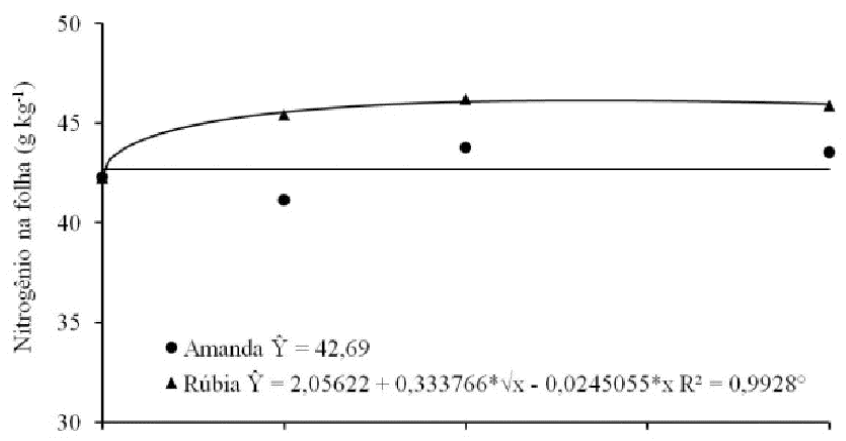

D.

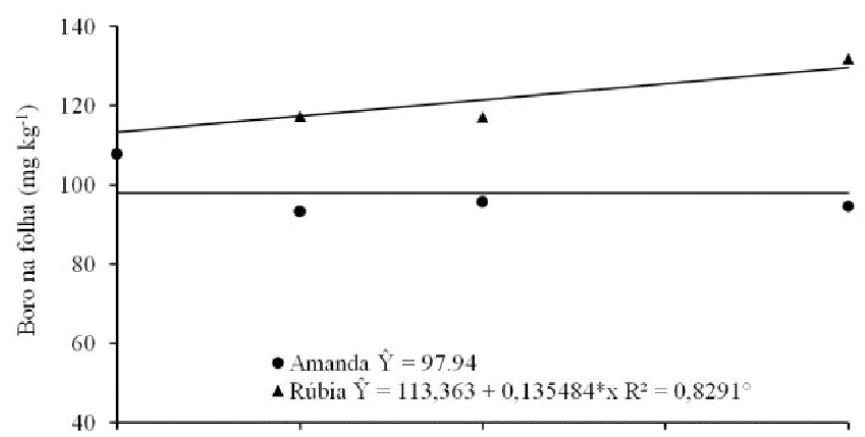

F.

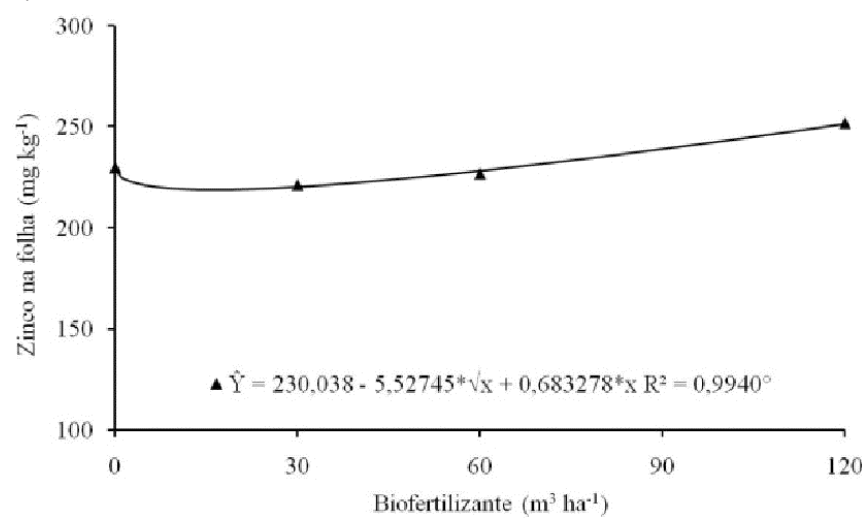

Figura 1. Índice SPAD (A) e teores foliares de nitrogênio (B), magnésio (C), boro (D), ferro (E) e zinco (F) em plantas de pimentão cv. Amanda e Rubia adubadas com biofertilizante de suíno

Os teores foliares de $\mathrm{P}$ e K não diferiram $(\mathrm{p}>0,05)$ entre as doses de biofertilizante e tampouco não foram diferentes entre as cultivares. Os valores médios correspondentes foram de 2,80 e 45,82 $\mathrm{g} \mathrm{kg}^{-1}$. Os teores foliares de $\mathrm{P}$ e K se encontravam dentro da faixa considerada adequada para o pimentão, que é de 2 a 7 e 40 a $60 \mathrm{~g} \mathrm{~kg}^{-1}$, respectivamente (Trani \& Raij, 1997).

Os teores foliares médios de $\mathrm{Ca}\left(23,53 \mathrm{~g} \mathrm{~kg}^{-1}\right)$ e Mn $(86,94$ $\left.\mathrm{mg} \mathrm{kg}^{-1}\right)$ na cv. Rubia foram superiores aos teores foliares de Ca $\left(21,49 \mathrm{~g} \mathrm{~kg}^{-1}\right)$ e $\mathrm{Mn}\left(76,00 \mathrm{mg} \mathrm{kg}^{-1}\right)$ na cv. Amanda mas para as duas cultivares os teores de $\mathrm{Ca}$ e $\mathrm{Mn}$ se mantiveram na faixa adequada para o pimentão, ou seja, de 10 a $35 \mathrm{~g} \mathrm{~kg}^{-1}$ e 30 a 250 $\mathrm{mg} \mathrm{kg}^{-1}$, respectivamente (Trani \& Raij, 1997) e próximos ao teor crítico apresentado por Fontes (2001). Nascimento Júnior (1998) avaliou o efeito da aplicação de $\mathrm{N}$ e $\mathrm{K}$ via água de irrigação por gotejamento na cultura do pimentão cv. Magali e constatou valores foliares para $\mathrm{K}, \mathrm{Ca}$ e $\mathrm{Mg}$, aos $67 \mathrm{DAT}$, próximos aos observados neste estudo. Para Ribeiro et al. (2000) o limite mínimo para o Ca nas folhas é de 24,3 $\mathrm{g} \mathrm{kg}^{-1}$. Marcussi (2005) observou, avaliando os teores de macronutrientes em folhas de pimentão, teor médio de cálcio de $20,5 \mathrm{~g} \mathrm{~kg}^{-1}$, aos 40 dias após o transplantio. Alguns autores constataram, nas folhas de pimentão coletadas no início da floração, teores, em $\mathrm{g} \mathrm{kg}^{-1}$, variando de: 30 a $60 ; 2$ a 8 e 25 a 60 respectivamente para N, $P$ e K (Melo et al., 2000; Ribeiro et al., 2000; Oliveira et al., 2004; Marcussi, 2005). Desta forma, os teores foliares de N, P e K observados neste trabalho se encontram nas faixas observadas por esses autores.

O teor foliar de S não foi alterado pelas doses de biofertilizante sendo maior na cv. Amanda $\left(4,18 \mathrm{~g} \mathrm{~kg}^{-1}\right)$ em relação à cv. Rubia $\left(2,97 \mathrm{~g} \mathrm{~kg}^{-1}\right)$. O teor de S na cv. Amanda foi semelhante ao observado no pimentão cultivar Elisa, sob fertirrigação (Marcussi, 2005). O teor foliar de Mg, para a cv. Amanda decresceu com o aumento das doses de biofertilizante até a dose de $65 \mathrm{~m}^{3} \mathrm{ha}^{-1} \mathrm{e}$ a partir daí foi constante, igual a $5,38 \mathrm{~g} \mathrm{~kg}$ 1, enquanto na cv. Rubia o teor médio de $\mathrm{Mg}$ foi de $6,27 \mathrm{~g} \mathrm{~kg}^{-1}$ (Figura 1C). Os teores foliares de Mg se apresentaram dentro 
da faixa considerada adequada ( 3 a $10 \mathrm{~g} \mathrm{~kg}^{-1}$ ), segundo Trani \& Raij (1997).

Os teores foliares de B foram superiores para a cv. Rubia sendo o maior valor $\left(129,62 \mathrm{mg} \mathrm{kg}^{-1}\right)$ estimado na maior dose aplicada, mas para a cv. Amanda não houve resposta à aplicação do biofertilizante com valor médio de $97,94 \mathrm{mg}$ $\mathrm{kg}^{-1}$ (Figura 1D). Para os teores foliares de Fe e Zn não houve diferença entre as cultivares. Os teores de Fe apresentaram redução com as doses de biofertilizante sendo o mínimo valor (194,06 $\mathrm{mg} \mathrm{kg}^{-1}$ ) estimado com $74 \mathrm{~m}^{3} \mathrm{ha}^{-1}$ (Figura 1E) enquanto que os teores de $\mathrm{Zn}$ apresentaram aumento com as doses de biofertilizante e o maior valor $\left(251,48 \mathrm{mg} \mathrm{kg}^{-1}\right)$ foi estimado na maior dose aplicada (Figura 1F). Para todos esses nutrientes os teores foliares se mantiveram dentro ou acima da faixa considerada adequada para o pimentão (Trani \& Raij, 1997). De acordo com Marcussi (2005) existe forte associação entre a absorção de nutrientes e o desenvolvimento da planta sendo a produtividade extremamente dependente desta associação e do movimento de nutrientes dentro da planta. Em geral, o teor de nutrientes nas plantas de pimentão varia de acordo com o seu desenvolvimento. Daí a importância de se saber o teor de nutrientes na planta de modo a se avaliar seu respectivo estado nutricional e o momento certo de se aplicar esses nutrientes (Marcussi \& Villas-Boas, 2003).

A cultivar Rubia apresentou maior produtividade precoce de frutos, 13,36 tha ${ }^{-1}$ estimada com a maior dose de biofertilizante enquanto, por outro lado, a 'Amanda' produziu em média 7,98 t ha $\mathrm{a}^{-1}$ (Figura 2A). A produtividade precoce é representada pela soma das produções referentes às três primeiras colheitas

A.

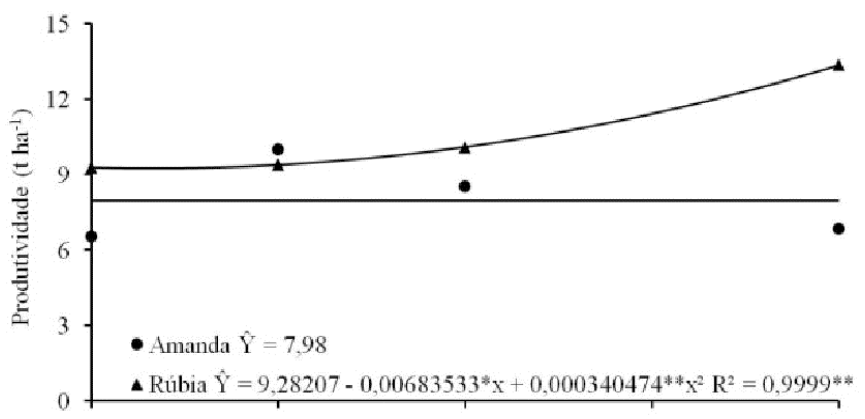

C.

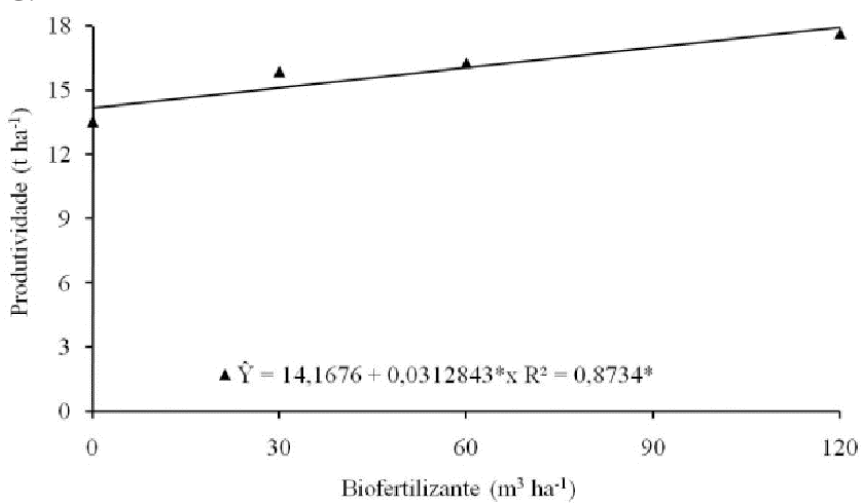

quando as plantas estão jovens e vigorosas e, por isso, é bastante representativa da produtividade de frutos da classe extra; mesmo assim, a produtividade de frutos extra não apresentou diferença entre as cultivares alcançando máxima produtividade 15,39 t ha $^{-1}$ estimada com $110 \mathrm{~m}^{3} \mathrm{ha}^{-1}$ de biofertilizante (Figura 2B). Os frutos desta classe são os de maior valor comercial.

A produtividade de frutos das classes especial e primeira foi pouco representativa e não houve efeito de doses de biofertilizante na produtividade de frutos dessas classes cujo valor médio foi de $1,02 \mathrm{t} \mathrm{ha}^{-1}$ para a classe primeira $\mathrm{e}$ para a especial observou-se maior produtividade para $\mathrm{cv}$. Rubia com 4,47 t ha ${ }^{-1}$ e 'Amanda' com 3,16 t ha $\mathrm{t}^{-1}$. A cv. Rubia apresentou maior produtividade de frutos comercializáveis $21,45 \mathrm{t} \mathrm{ha}^{-1}$ comparada com a da cv. Amanda 17,22 $\mathrm{t} \mathrm{ha}^{-1}$. Essas produtividades são próximas àquelas obtidas por Oliveira et al. (2004) de 25,5 e de 10,7 tha ${ }^{-1}$ de pimentão, cultivar All Big, obtidas com a aplicação de 5\% de urina de vaca na presença e ausência de NPK, respectivamente, sendo a produtividade média de 19,8 $\mathrm{t} \mathrm{ha}^{-1}$ de frutos comerciais, na presença de NPK e de urina de vaca. Araújo et al. (2007) também trabalharam com a cultivar All Big e obtiveram, na presença de biofertilizante aplicado no solo, produção média de $410,6 \mathrm{~g}$ de frutos por planta e produtividade de $8,3 \mathrm{tha} \mathrm{a}^{-1}$ de frutos comerciais em função das doses de esterco bovino.

Com o aumento das doses de biofertilizante, independente da cultivar, observou-se aumento na produtividade de frutos não comercializáveis. A maior produtividade $\left(17,92 \mathrm{t} \mathrm{ha}^{-1}\right)$ foi obtida na dose de $120 \mathrm{~m}^{3} \mathrm{ha}^{-1}$ de biofertilizante (Figura 2C). A grande produção de frutos não comerciais, em especial nas

B.

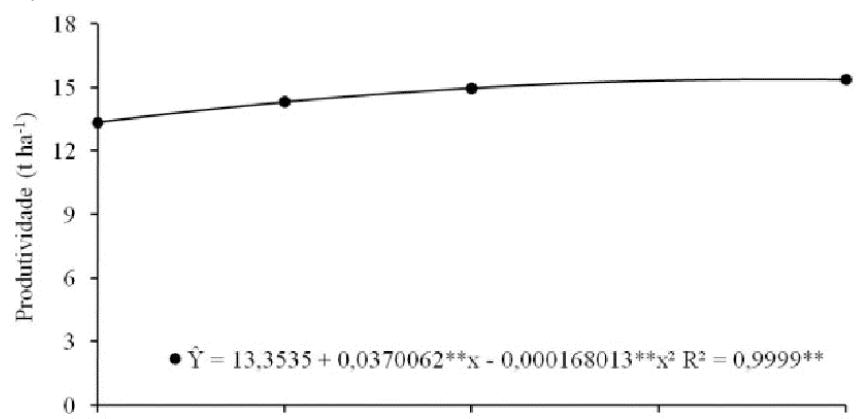

D.

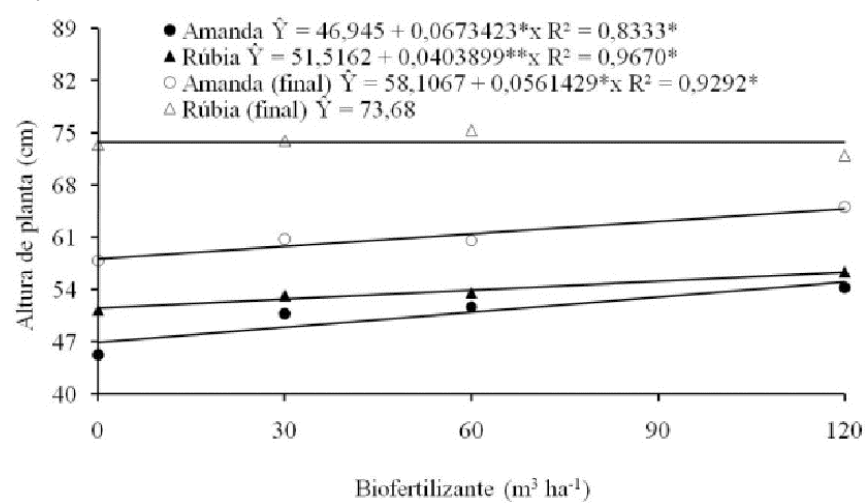

Figura 2. Produtividade precoce de frutos $(A)$, produtividade de frutos extra $(B)$, produtividade de frutos não comercializáveis (C) e altura das plantas aos 78 dias de idade e no final do ciclo (D) de pimentão cv. Amanda e Rubia adubadas com biofertilizante de suíno 
maiores doses de biofertilizante, foi associada ao maior ataque por pássaros e roedores nos frutos maiores, além da queima e murcha provocada pelo sol, nas duas cultivares.

Em geral, a colheita de frutos verdes tem início em torno de 110 dias e de frutos maduros aos 150 dias após a semeadura; em consequência, os frutos maduros apresentam maior custo de produção em virtude do tempo para a maturação, da necessidade de mais medidas preventivas de controle visando garantir a sanidade das plantas e a integridade dos frutos, porém o valor de mercado é maior para frutos maduros em relação aos frutos verdes; logo, justifica-se o investimento para a produção de frutos maduros normalmente feita em ambiente protegido; contudo, o pequeno produtor ainda pode fazer o cultivo em campo, a céu aberto, pois a produtividade obtida é satisfatória, de acordo com os resultados obtidos neste trabalho.

As plantas da cv. Rubia apresentaram maior altura que as da cv. Amanda desde o início da frutificação até o final do ciclo. Aos 40 dias após o transplante das mudas a altura variou de 51,51 a $56,36 \mathrm{~cm}$ para a cv. Rubia e de 46,94 a 55,02 $\mathrm{cm}$ para 'Amanda'. No final do ciclo a altura das plantas da cv. Rubia não foi alterada em função das doses de biofertilizante cujo valor médio foi 73,68 cm enquanto da cv. Amanda variou de 58,10 a 64,84 cm (Figura 2D). De modo geral, as maiores altura de plantas foram obtidas na maior dose de biofertilizante $\left(120 \mathrm{~m}^{3}\right.$ $\mathrm{ha}^{-1}$ ) o que pode ser justificado pelo maior desenvolvimento devido à maior disponibilidade de nutrientes para as plantas.

A aplicação de biofertilizante de suíno via solo permitiu, à planta de pimentão, atingir teores foliares adequados de nutrientes provavelmente em função do fornecimento de macro e micronutrientes, do parcelamento das aplicações e sua liberação durante o ciclo da cultura. De forma semelhante, Santos et al. (2012) observaram incremento na produção de abóbora híbrida com doses de biofertilizante de suíno até 40 $\mathrm{m}^{3} \mathrm{ha}^{-1}$; esses autores sugerem a combinação de uma fonte de $\mathrm{P}$ para completar a baixa disponibilidade deste nutriente no biofertilizante.

No presente trabalho a aplicação de $300 \mathrm{~kg} \mathrm{ha}^{-1}$ de $\mathrm{P}_{2} \mathrm{O}_{5}$ na forma de termofosfato natural (Yorim Master ${ }^{\circledR}$ ) permitiu maior disponibilidade de $\mathrm{P}$ para as plantas, atendendo à necessidade da cultura do pimentão (Ribeiro et al., 1999). Tal procedimento é sempre recomendado quando se usam resíduos orgânicos para evitar a contaminação do solo uma vez que a aplicação sucessiva desses resíduos em doses elevadas determina o aumento na concentração de nutrientes no solo e pode, inclusive, atingir concentrações tóxicas para as plantas.

A percentagem de massa seca dos frutos diferiu entre as cultivares haja vista que para a cv. Rubia não houve efeito do biofertilizante cujo valor médio foi de $8,03 \%$. Considerando a produtividade média de $21,45 \mathrm{t} \mathrm{ha}^{-1}$ a produção de massa seca de frutos foi de $1722 \mathrm{~kg} \mathrm{ha}^{-1}$. Para a cv. Amanda a percentagem de massa seca nos frutos variou de 7,31 a 7,86\%, sendo o menor valor estimado com $99 \mathrm{~m}^{3} \mathrm{ha}^{-1}\left(\hat{\mathrm{Y}}=7,86577-0,110854^{\star *} \sqrt{\mathrm{x}}+\right.$ $\left.0,0558168^{\star} x ; R^{2}=0,9996^{*}\right)$.

Os teores de sólidos solúveis presentes nos frutos maduros de pimentão não foram influenciados pelas doses de biofertilizante e não diferiram entre as cultivares sendo observado valor médio de 6,49 Brix. Evangelista et al. (2008) observaram teores semelhantes de sólidos solúveis em frutos maduros de pimentão 'Rubia' minimamente processados, no formato de tiras e rodelas (6,27 Brix) no tempo zero de armazenamento.

Neste estudo observou-se maior índice SPAD e maior teor de $\mathrm{N}$ nas folhas da cv. Rubia em relação à cv. Amanda. Os teores foliares de nutrientes se apresentaram adequados ou acima da faixa considerada adequada para o pimentão. Considerando as respostas diferenciadas à aplicação do biofertilizante na produtividade comercial, produtividade precoce e de frutos extras de pimentão utilizando-se técnicas de cultivo orgânico, verifica-se o efeito positivo do biofertilizante suíno na produção de frutos maduros, com discreta diferença entre os híbridos, no cultivo a campo.

\section{CONClusões}

1. A aplicação do biofertilizante de suíno via solo permite melhorar o estado nutricional e produtivo das cultivares de pimentão colorido, em sistema de cultivo orgânico a campo, com reflexos positivos nos teores foliares de nutrientes e nas produtividades comercial, precoce e de frutos extras.

2. A cultivar Rubia apresenta melhor resposta à aplicação do biofertilizante com maior produtividade precoce e comercial de frutos, 13,36 e 21,45 $\mathrm{t} \mathrm{ha}^{-1}$ enquanto a cv. Amanda produz em média 7,98 e 17,45 $\mathrm{t} \mathrm{ha}^{-1}$, respectivamente.

3. Assim, o biofertilizante de suíno apresenta potencial para fins de fertilização não convencional de solo para o cultivo de pimentão colorido podendo também reduzir os impactos ambientais associados ao descarte de dejetos de suíno no ambiente.

\section{Agradecimentos}

À Fundação de Amparo à Pesquisa do Estado de Minas Gerais (FAPEMIG) pelo auxílio financeiro ao projeto e concessão das bolsas de pesquisa BIPDT e PDJ. Ao Conselho Nacional de Desenvolvimento Científico e Tecnológico (CNPq) pela bolsa de produtividade em pesquisa ao primeiro autor.

\section{Literatura Citada}

Araújo, E. M.; Oliveira, A. P.; Cavalcante, L.F .; Pereira, W. E.; Brito, N. M.; Neves, C. M. L.; Silva, E. E. Produção do pimentão adubado com esterco bovino e biofertilizante. Revista Brasileira de Engenharia Agrícola e Ambiental, v.11, p.466-470, 2007.

CEAGESP - Companhia de Entrepostos e Armazéns Gerais de São Paulo. Normas de classificação do pimentão para o Programa Brasileiro para melhoria dos padrões comerciais e embalagens de hortigranjeiros. <http://www.alimentares. com/pimentas/_file/norma_pimentoes.pdf>. 12 Abr. 2010.

Cunha, T. J. F.; Blancaneaux, P.; Calderano Filho, B.; Carmo, C. A. F. S.; Garcia, N. C. P.; Lima, E. M. B. Influência da diferenciação pedológica no desenvolvimento da seringueira no município de Oratórios, MG. Pesquisa Agropecuária Brasileira, v.35, p.145-155, 2000. 
EMBRAPA - Empresa Brasileira de Pesquisa Agropecuária. Manual de análises químicas de solos, plantas e fertilizantes. Brasília: Embrapa Informação Tecnológica, 2009. 627p.

Evangelista, R. M.; Godoy, A. R.; Cardoso, A. I. I. Vieites, R. L. Qualidade de pimentão 'rubia' minimamente processado e armazenado sob refrigeração. Revista Ceres, v.55, p.338343, 2008.

Factor, T. L.; Araújo, J. A. C.; Vilella Júnior, L. V. E. Produção de pimentão em substratos e fertirrigação com efluente de biodigestor. Revista Brasileira de Engenharia Agrícola e Ambiental, v.12, p.143-149, 2008.

Figueiredo, P. G; Tanamati, F. Y. Adubação orgânica e contaminação ambiental. Revista Verde de Agroecologia e Desenvolvimento Sustentável, v.5, p.1-4, 2010.

Fontes, P. C. R. Diagnóstico do estado nutricional das plantas. Viçosa: UFV, 2001. 122p.

Fontes, P. C. R.; Araújo, C. Use of chlorophyll meter and plant visual aspect for nitrogen management in tomato fertirrigation. Journal of Applied Horticulture, v.8, p.8-11, 2006.

Henz, G. P.; Costa, C. S. R.; Carvalho, S.; Banci, C.A. Como cultivar pimentão. Caderno Técnico da edição da Cultivar HF, n.42, p.1-7, 2007.

Marcussi, F. F. N. Uso da fertirrigação e teores de macronutrientes em planta de pimentão. Engenharia Agrícola, v.25, p.642650, 2005.

Marcussi, F. F. N.; Godoy, L. J. G.; Villas-Bôas, R. L. Fertirrigação nitrogenada e potássica na cultura do pimentão baseada no acúmulo de N e P pela planta. Irriga, v.9, p.41-51, 2004.

Marcussi, F. F. N.; Villas-Bôas, R. L. Teores de micronutrientes no desenvolvimento da planta de pimentão sob fertirrigação. Irriga, v.8, p.120-131, 2003.

Melo, S. C.; Pereira, H. S.; Vitti, G. C. Efeito de fertilizantes orgânicos na nutrição e produção do pimentão. Horticultura Brasileira, v.18, p.200-203, 2000.

Moretti, S. M. L.; Bertoncini, E. I.; Abreu Júnior, C. H. Aplicação do método de mineralização de nitrogênio com lixiviação para solo tratado com lodo de esgoto e composto orgânico. Revista Brasileira de Ciência do Solo, v.37, p.622-631, 2013.

Mossini, S. A. G.; Kemmelmeier, C. A árvore nim (Azadirachta indica A. Juss): Múltiplos usos. Acta Farmacêutica Bonaerense, v.24, p.139-148, 2005.
Nascimento Júnior, N. A. Efeito da aplicação de N e K via água de irrigação por gotejamento na cultura do pimentão em ambiente protegido. Botucatu: UEP, 1998. 92p. Dissertação Mestrado

Oliveira, A. P.; Paes, R. A.; Souza, A. P.; Dornelas C. S. M.; Silva R. A. Produção de pimentão em função da concentração de urina de vaca aplicada via foliar e da adubação com NPK. Agropecuária Técnica, v.25, p.37-43, 2004.

Ribeiro, A. C.; Guimarães, P. T. G.; Alvarez, V. V. H. Recomendações para o uso de corretivos e fertilizantes em Minas Gerais: 5a Aproximação. Viçosa: Comissão de Fertilidade do Solo do Estado de Minas Gerais, 1999. 359 p.

Ribeiro, G. L.; Lopes, J. C.; Martins Filho, S.; Ramalho, S. S. Adubação orgânica na produção do pimentão. Horticultura Brasileira, v.18, p.134-137, 2000.

Santos, M. R.; Sediyama, M. A. N.; Moreira, M. A.; Megguer, C. A.; Vidigal, S. M. Rendimento, qualidade e absorção de nutrientes pelos frutos de abóbora em função de doses de biofertilizante. Horticultura Brasileira, v.30, p.160-167, 2012.

Sediyama, M. A. N.; Santos, M. R.; Vidigal, S. M.; Salgado, L. T.; Pedrosa, M. W.; Jacob, L. L. Produtividade e estado nutricional do quiabeiro em função da densidade populacional e do biofertilizante suíno. Bragantia, v.68, p.913-920, 2009a.

Sediyama, M. A. N.; Vidigal, S. M.; Santos, M. R.; Salgado, L. T. Rendimento de pimentão em função da adubação orgânica e mineral. Horticultura Brasileira, v.27, p.294299, $2009 b$.

Trani, P. E.; Raij, B. van. Hortaliças. In: Recomendações de adubação e calagem para o Estado de São Paulo. Raij, B.van.; Cantarella, H.; Quaggio, J. A.; Furlani, A. M. C. (ed.). Campinas: IAC, 1997, p.157-164. Boletim Técnico, 100

Vidigal, S. M.; Sediyama, M. A. N.; Pedrosa, M. W.; Santos, M. R. Produtividade de cebola em cultivo orgânico utilizando composto à base de dejetos de suínos. Horticultura Brasileira, v.28, p.168-173, 2010.

Waquin, V.; Andrade, A. T. Nutrição mineral e diagnose do estado nutricional das hortaliças. Lavras: UFLA/FAEPE, 2004. 80p. 